\title{
Initiating eLearning via Workflow Management
}

\author{
Carlo Simon, Nadja Reckmann, and Paula M. C. Swatman \\ University of Koblenz-Landau,Koblenz, Germany \\ simon@uni-koblenz.de, reckmann@uni-koblenz.de, swatmanp@uni-koblenz.de
}

\begin{abstract}
Both eLearning and Workflow Management Systems are widely used today to support Content Management. Workflow Management is designed to organise office processes in as optimal a way as possible by strictly structuring work, while eLearning enables a very flexible approach to the learning of new skills or information. In this paper, we suggest the integration of eLearning into Workflow Management, so that a demand for learning is registered automatically by the Workflow Management System, and is delivered via the Internet to provide a fully distributed solution for today's organisations. Such a demand exists, for example, when an employee has to conduct a certain task for the first time. With the aid of a Learner Management System this tailored learning can be configured in a maximally efficient way with respect to each learner's prior knowledge. We are currently testing our results in cooperation with one of the largest German insurance companies.
\end{abstract}

Keywords: eLearning, Workflow Management

\section{INTRODUCTION}

Over the past few years, eLearning has become an important part of eBusiness. A possible explanation for this lies in the idea that since humans have used texts and images to represent knowledge for thousands of years and since these can readily be stored and exchanged with the aid of computers, eLearning Environments can now be produced with little difficulty.

The advantages of efficiently operating eLearning are self-evident: virtual teachers are available 24 hours a day and 7 days a week; and teaching materials can be easily adapted to the learner's individual needs. Additional advantages normally relate to particular learning situations (Rosenberg, 2001).

These benefits have meant that virtual courses providing instruction and information in the field of advanced vocational training are particularly popular. For the developers of such courses, the challenge usually lies in the educational or technical aspects. Undoubtedly both definition and realisation of a sound

\footnotetext{
The original version of this chapter was revised: The copyright line was incorrect. This has been corrected. The Erratum to this chapter is available at DOI: 10.1007/978-0-387-35617-4_48 
educational concept on the one hand, plus the implementation of attractive and well-integrated user interfaces which motivate learners to keep on concentrating on the learning material are of high relevance. But impressive as such an environment is, it is not sufficient for truly effective eLearning.

Learning should not only be restricted to precisely specified periods. More reasonably, one should be able to learn whenever there is a need to do so, i.e. whenever there is a demand for knowledge. This kind of learning is usually known as learning on demand and is nowadays often combined with Knowledge Management Systems (Sanchez and Heene, 1997b; Borghoff and Pareschi, 1998).

Knowledge Management is a recent development within Computer Science dealing with the "systematic, explicit, and deliberate building, renewal, and application of knowledge to maximize an enterprise's knowledge-related effectiveness and returns from its knowledge assets" (Wiig, 1997). It is based on an understanding of knowledge as "information that has been organised and analysed to make it understandable and applicable to problem solving or decision making" (Turban, 1992). A broad definition of both terms is discussed in (Beckman, 1999).

Knowledge Management Systems have become especially popular in the field of Electronic Document Management Systems (EDMS), where the collection of data is a major issue (Koulopulos and Frappaolo, 1995). EDMS are particularly relevant to eLearning environments because both have at least one component in common: a module which provides knowledge management facilities like classifying and querying both structured and unstructured data.

Implementing an eLearning Environment is not only a question of education and technology but also an administrative task. Learning has to be integrated directly into work. (Rosenberg, 2001) describes in detail several strategies for integrating eLearning into a company's organisation. Rosenberg points out that without a corporate culture designed to promote its employees' abilities and knowledge, eLearning environments cannot be successfully introduced into a company. Unfortunately, no operational approach to integrating learning into daily routine is described by the author.

One way to achieve this integration is by combining Electronic Document Management Systems with an eLearning Environment. This can be done by using the Workflow Management System which is usually integrated into an Electronic Document Management System. In such an integrated environment, learning could be coupled to individual tasks which must be fulfilled within the workflows.

Developing such an integrated system for vocational applications, however, cannot simply be achieved by a single software developer, but is a cooperative venture. In this paper, we suggest that Internet-based distribution is essential for the eLearning material because it can be added to an existing Workflow 
Management System. The combination of an eCommerce approach to the delivery of material and a Workflow Management based core system offers maximally effective support for the use of the Workflow Management System, together with a highly efficient distributed approach to vocational learning in a corporate environment.

This paper is organised as follows: section 2 provides a brief overview of the history and current state of eLearning. Section 3 describes the most significant components of Electronic Document Management Systems, where we focus particularly on the underlying workflow philosophy upon which such systems are usually based. Section 4 combines these themes by coupling learning units to work items in workflows. Section 5 discusses the way in which an Internetbased eLearning environment could (and should) be attached to an existing Workflow Management System. Section 6 depicts a scenario to explain the application of our approach. Finally, the paper summarises the outcomes and explains the advantages of the approach we propose.

\section{2. eLearning ENVIRONMENTS}

In today's corporate world learning is not so much an option as a necessity, for which two major driving forces exist:

- The integration of complex work activities (tasks) into company-wide workflows, or even into inter-organisational supply chains, means that individual activities can no longer be processed without understanding their effect on the totality of the organisation.

- Rapidly changing (information) technologies lead inevitably to the adaptation and evolution of business processes. The introduction of the Internet, in particular, changes the way humans think about how to organise and distribute workloads. (Sander, 1999; Kollinger, 2001).

These changes are accompanied by an increasing demand for learning.

Because of the significant amount of specialist learning and teaching required today, several approaches to computer-supported teaching and learning have been developed. These learning environments also provide the opportunity (especially in the field of advanced vocational training) to gain the following advantages: Firstly, learning is possible 24 hours a day/7 days a week; secondly, the teaching material available can be adapted to cater for individual needs including repetition, varying levels of detail and explanation, and flexibility concerning the order in which the material is learned; thirdly, advanced learning materials also allow for interactive learning and contain attractive multimedia presentations; and, finally, traveling costs can be decreased drastically (Kollinger, 2001). 
The most popular form of computer supported teaching and learning is Computer Based Training (CBT) (Dijkstra et al., 2001), which can be defined as 'an interactive learning experience between a learner and a computer in which the computer provides the majority of the stimulus, the learner must respond, and the computer analyzes the response and provides feedback to the learner'. Indeed, in Germany $90 \%$ of all computer supported teaching and learning is currently CBT (Harhoff et al., 2001).

In (Bodendorf and Hofmann, 1993), the following types of computer supported teaching and learning systems are distinguished:

- Help system

- Drill \& practice systems which deal with the training of existing knowledge

- Tutorials which allow interactive dialogs between learner and computer

With the increasing popularity of Internet technologies, CBT solutions have been extended by means which promote communication between teachers and students, as well as that existing among students. Techniques used for this communication are chat, video conferences, email, and news groups.

The latest development in the field of CBT is eLearning or Internet-based Learning. eLearning is a special form of Distance Learning which uses the Internet to distribute learning materials. eLearning is often categorised into Web-based Training and Online Learning, where the second category describes the distribution of learning material by a specialised Learning Service Provider.

Using Internet technologies offers another advantage over other forms of CBT. Since Internet browsers can be installed on nearly every desktop, the availability of learning material is increased. When an employee recognises a need for information and therefore for learning, s/he does not have to check seminar catalogues to find appropriate courses. Instead, immediate access to lectures offered online is possible. This high level of availability (both in terms of time and access to material) enables learning on demand.

As the number of courses and of educated learners increases beyond a certain point, the management of resources and users becomes sufficiently complex to require the assistance of a Learning Management System. From an educational point of view, a major benefit of such systems is that they are able to handle the administration and management of a variety of different approaches to teaching - allowing the use of different media types and supporting both synchronous and asynchronous communication channels. A second major advantage of Learning Management Systems is that they enable automatic update of learning materials over the Internet, by means of Content Management System functionality. A third advantage is the potential these systems offer to integrate a learner tracking component, enabling the registration and analysis of the courses taken by a 
particular user, his/her preferred presentation form, and the success of already conducted training. This information allows trainers to individually configure employees' further training in an Individual Education Program (Block and Dobell, 1999).

All the approaches to eLearning explained above have in common the fact that learning is tightly coupled to imparting knowledge by means of a (virtual) teacher. This perspective on learning, however, ignores humans ability to improve their knowledge independently of predefined learning materials. (Sanchez and Heene, 1997b) suggest that this limitation can be overcome by the integration of eLearning and Knowledge Management, although such integration has to be implemented on both a technical and an organisational level.

In section 4, we propose the implementation of just such an integration, by allowing to access learning materials and information required for work through a single access point. We go even further, suggesting that in such an environment it is possible to automatically detect a demand for learning - something which is only possible at present when employees or their superiors notice a need for or a lack of training.

\section{ELECTRONIC DOCUMENT MANAGEMENT SYSTEMS AND WORKFLOW}

Development and introduction of Electronic Document Management Systems were the result of the observation that offices appeared to be drowning in paper. However, merely changing a paper representation of a business issue into an electronic representation is not a real solution, because it is not the medium which causes the problems, but the availability of the information contained in the documents (Koulopulos and Frappaolo, 1995). Different components of Electronic Document Management Systems have been identified as being absolutely essential for workflow systems, and we discuss these components in this section.

The first typical characteristic of an EDMS is that it usually offers a single point of access to the documents managed (cf. figure 1). The idea behind this is that, no matter in which document type information is formatted, it is accessible by one unique method. When texts are stored in an EDMS, imaging techniques are used for filing and a representation in plain text is used for text retrieval. The system also builds an index to the material, either manually or automatically. (Although a comprehensive discussion of text retrieval and retrieval of multimedia data is beyond the scope of this paper, a detailed explanation is provided in (Subrahmanian, 1998)).

Although the term document is obviously central in Electronic Document Management Systems, no precise definition is offered in the literature on this topic (see, for example, (Koulopulos and Frappaolo, 1995)). This is because an 


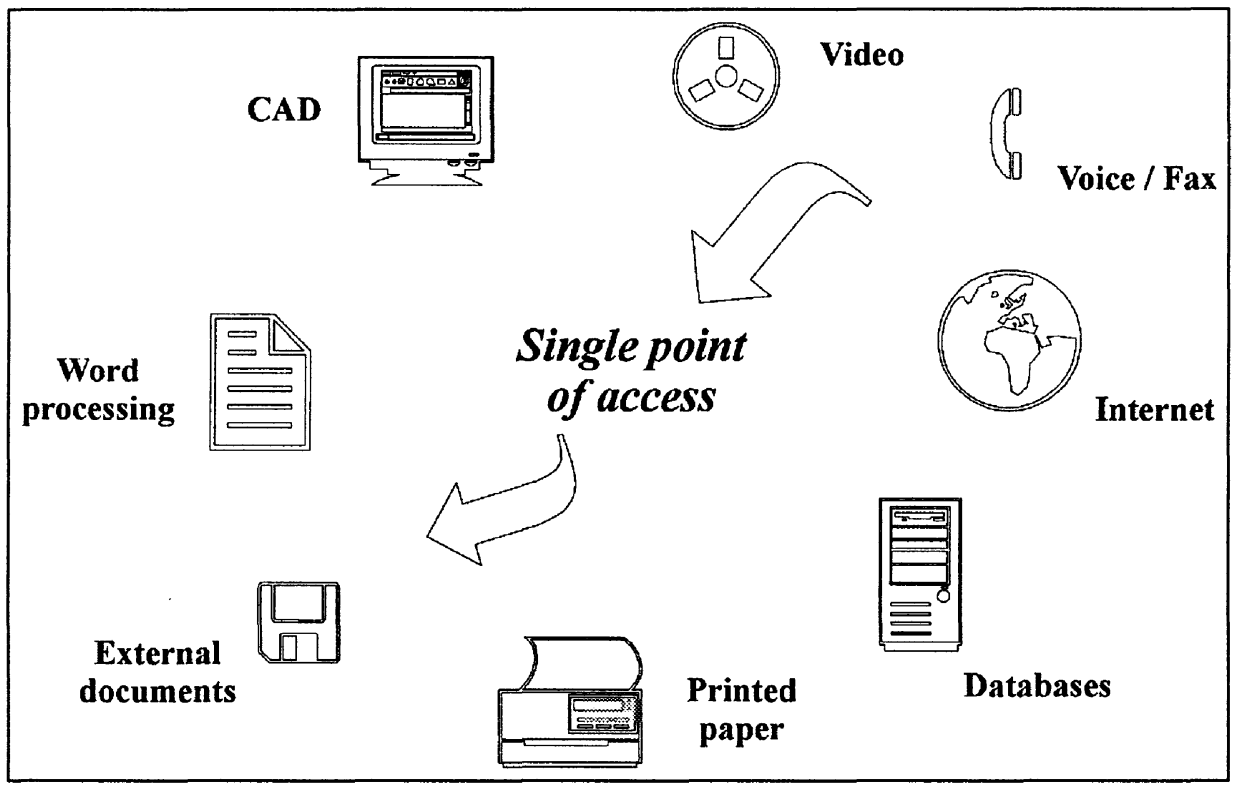

Figure 1. Single point of access

EDMS does not aim to organise documents but rather to organise human work, so that information has to be made available no matter what kind of document format it is represented by.

The expression workflow is now widely used to describe human work and the basic terms on this area are defined by the Workflow Management Coalition $(W f M C)$. A workflow is "the automation of a business process, in whole or part, during which documents, information or tasks are passed from one participant to another for action, according to a set of procedural rules". A Workflow Management System "defines, creates and manages the execution of workflows through the use of software, running on one or more workflow engines, which is able to interpret the process definition, interact with workflow participants and, where required, invoke the use of IT tools and applications" (WFM, 1996).

These fundamental definitions from the WfMC highlight the most important parts of workflow and systems from the point of view of automation:

- Workflow participants who perform the work. The term workflow participant "is normally applied to a human resource but it could conceptually include machine based resources such as an intelligent agent" (WFM, 1996).

An organisational role specifies a group of employees "exhibiting a specific set of attributes, qualifications and/or skills" (WFM, 1996). Instead of "workflow participant" the term "role player" is used. This highlights the fact that when a workflow is planned one does not think of individuals, but of tasks and of positions in an organisational structure which 
are implemented to fulfill this task. The assignment of a certain task to a specific individual is done while a process instance is executed.

- Activities are definitions of the elementary pieces of work of which a workflow is composed. The structure of a workflow specifies sequences, alternatives, and parallel occurrences of activities.

An activity can be performed manually (by humans) or automatically (by the Workflow Management System or by elementary tools for business automation).

A process instance is a workflow in execution, while an Activity instance is activity in execution.

The diagram in figure 2 illustrates the relationships between these elementary terms according to the WfMC (WFM, 1996).

In an organisation, employees get new or change existing roles, for example when new employees are taken on, when one employee deputises for another, or when one employee changes his/her position in the case of organisational restructuring. Each time an employee works on a certain activity for the first time, s/he must learn the objective(s) of this activity and must obtain instruction concerning what has to be done and in which sequence.

This last observation is crucial to our argument - and implies the following considerations. 


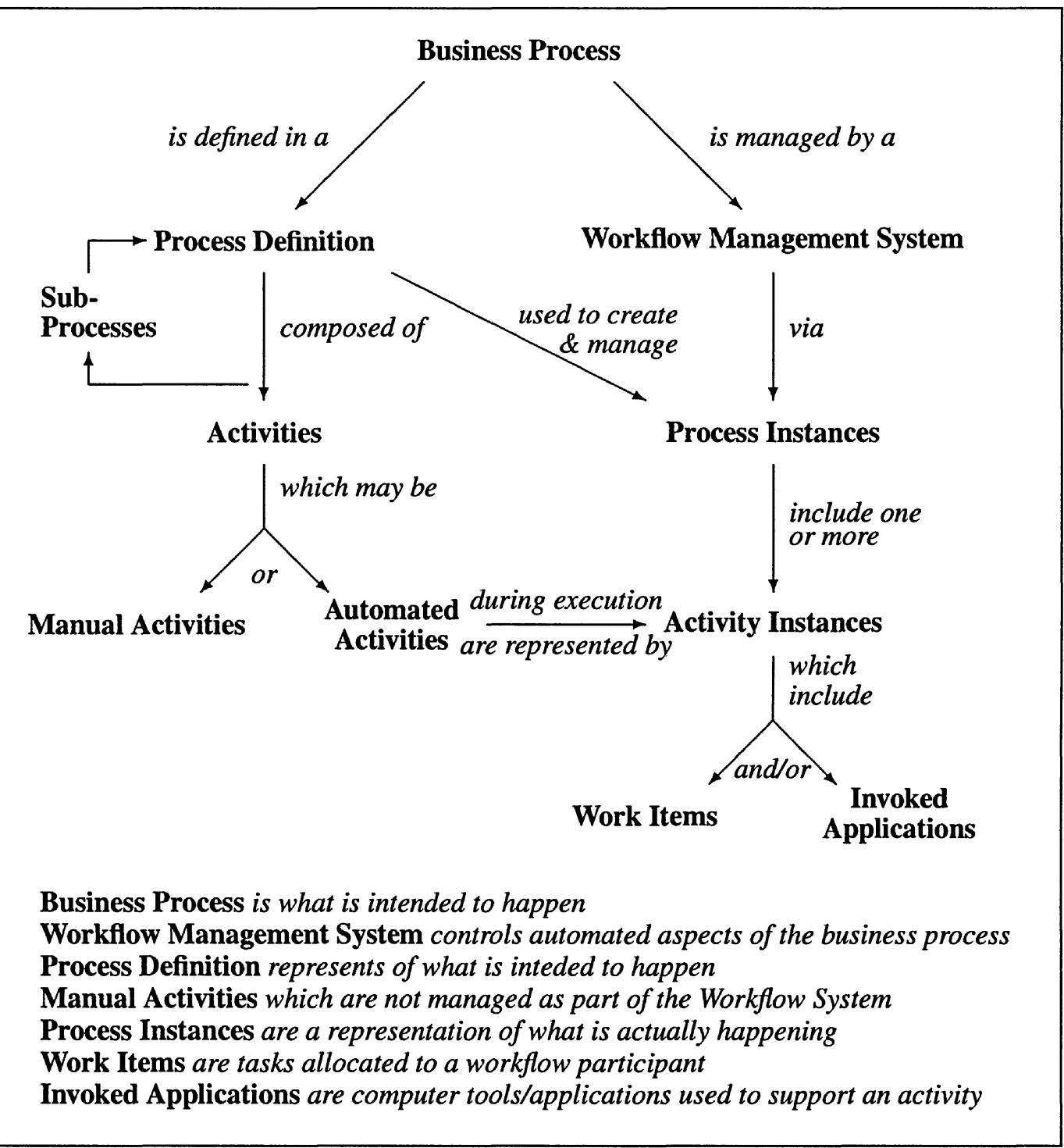

Figure 2. Relationships between basic workflow terminology 


\section{ACTIVITY CENTERED LEARNING}

In (Sanchez and Heene, 1997a), learning is defined as "a process which changes the state of knowledge of an individual or organization". Based on this definition, the authors correlate learning processes and the management of knowledge with one another. They are aiming to answer the following questions: how can an individual learn his/her company's knowledge to the level required; and how can a company participate in the knowledge of its employees? Answers to these questions are of great theoretical and practical relevance for the definition of Knowledge Management Systems.

Despite the obvious importance of these questions, a major text in the area of learning and Knowledge Management such as (Sanchez and Heene, 1997a) neither asks nor answers another important question which is tightly coupled to those formulated above: when should an employee request knowledge?

The reason why this question has not yet been answered might lie in the fact that learning, knowledge, and a company's workflows have not yet been considered as integral parts of companies' Information Systems.

Whenever an employee conducts a certain task for the first time, s/he needs assistance. Instruction might also be needed by someone who has not worked on a specific topic for a long time, or who has only worked on a complex task a few times.

In a Workflow Management System, identification and tracking of the tasks which have been conducted by an employee can be implemented very easily. Figure 3 extends that part of figure 2 which deals with activities processed by humans.

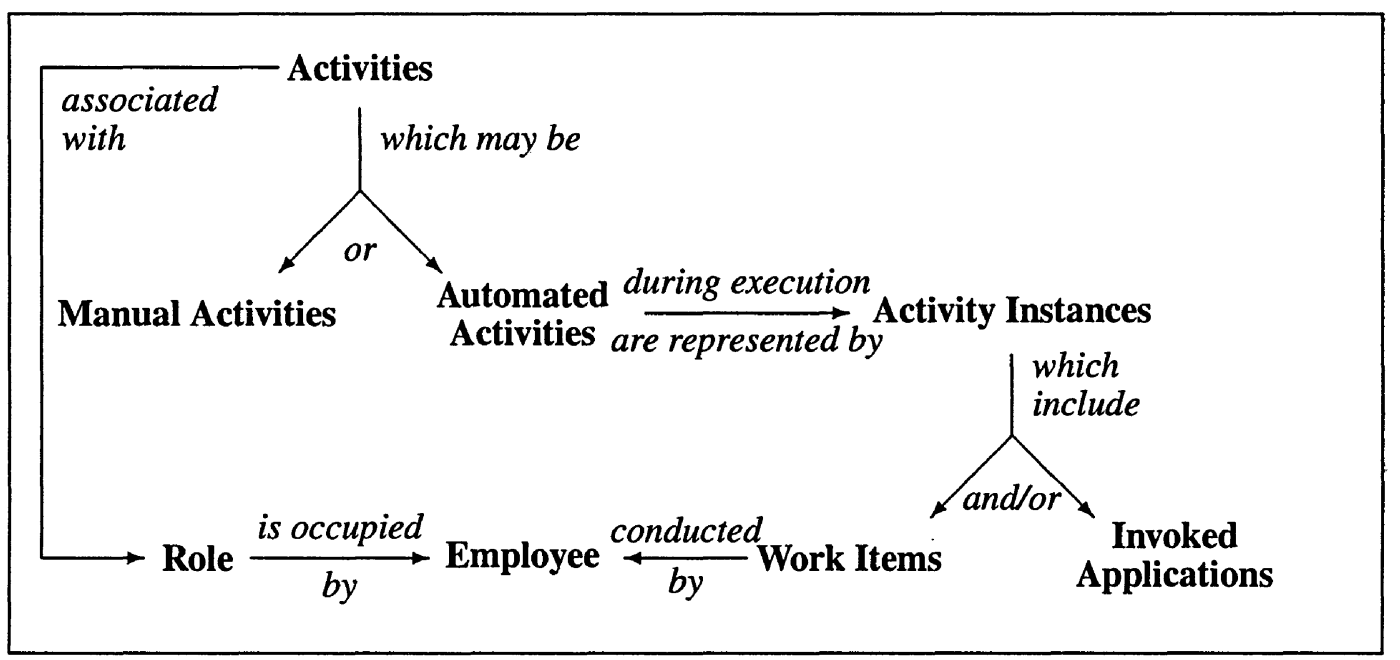

Figure 3. Activities and by whom they are being conducted 
Roles specifying which position in an organisation is responsible for a particular task are associated with activities. Work items are associated with employees who perform the work. The relation between role and employee is that an employee conducting a certain work item must be have the role associated with the respective activity.

For us, a worklist is "a list of work items associated with a given workflow participant" (WFM, 1996). (Note that in terms of the WfMC's definitions, a worklist could also be associated with a group of workflow participants who may share a common worklist. Such a definition, however, would not allow us to keep track of an individual's abilities, which is fundamental to the following argument.)

Now, an employee tracking system is implemented by storing each work item that is processed by an employee and removed from his/her worklist.

If the work of an employee is determined by a Workflow Management System, we can precisely specify what $\mathrm{s} / \mathrm{he}$ has to know and what abilities $\mathrm{s} / \mathrm{he}$ should have. We can distinguish between the following areas where knowledge and/or abilities are required:

\section{- Business Process}

Some activities might require a thorough understanding of the total process in which that activity is embedded (for example, when a customer asks for the status of his/her purchase order).

An explanation of the business process might comprise the whole process definition or only the definition of sub-processes.

\section{- Activities}

If a certain activity requires the collection or analysis of large amounts or distributed information, there is a clear need to understand how to implement this collection or analysis - and thus a demand for learning. Note, however, that this demand also exists for other kinds of activity, both manual or automated.

While a business process in total, or single activities which are a part of that business process, have to be explained to understand what has to be done, other parts of a Workflow Management System have to be explained in order to understand how to perform a certain task:

\section{- Workflow Management System}

A Workflow Management System is a software system which coordinates the work of its participants, offers a single point of access to all relevant documents and other information, and mirrors the organisational structure of the company it is used to support. All this functionality has to be 
explained to a new user. Here, we should distinguish between an overview of all functions, and instructions with respect to specific functions.

- Invoked Applications

Whenever a participant of a Workflow Management System has to work with an invoked application that is neither self-explanatory nor can be intuitively used, instructions should be provided by the Workflow Management System.

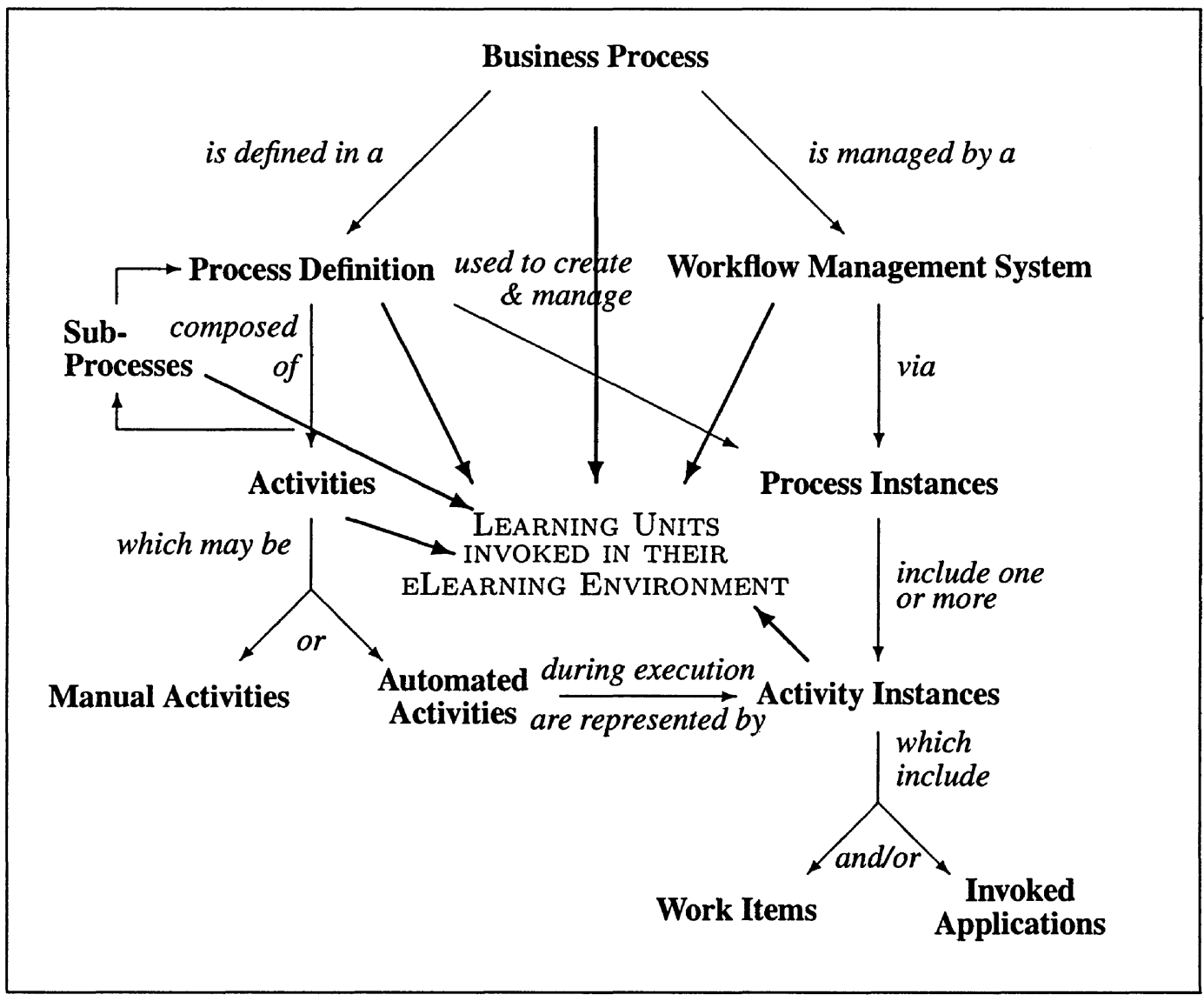

Figure 4. Association of learning units to the elements of a Workflow Management System

In figure 4, all the terms of the Workflow Management System introduced in figure 2, for which explanations an instructions might be required when the application is in use, are associated with Learning Units (using dotted lines for emphasis).

As already mentioned in section 2, Learning Management Systems usually provide a learner tracking component. This component and the user tracking component of the Workflow Management System could now cooperate through a Learning Demand Recognition Component which acts as a supervisor. For 
example, whenever a user has to perform a certain activity for the first time, the learning unit $L U$ associated with this activity, as well as all other associated learning units required to understand $L U$ and which in accordance with the learner tracking component have not yet been learned by the user are invoked, i.e. they are put into the user's worklist. This suggests that the priority of the learning unit should be higher than that of the task to be performed. Prioritisation can also be used to achieve the sequence in which the learning units must be followed up.

The combination of eLearning and Workflow Management offers a number of benefits to an organisation: integrated access to tasks and learning units through a single interface, and effective tracking of both needs and outcomes. In the next two sections of this paper, we explain how the fusion of these two applications can work in practice.

\section{INITIATING JUST-IN-TIME LEARNING}

As the previous sections have made clear, the integration of a component which can recognise a demand for learning into a Workflow Management System is technically feasible. The development of both eLearning Environments and Workflow Management Systems, however, is not an easy process; and the development of one of these application types cannot simply be enriched by the second as though it were a part of a jigsaw puzzle.

The paper has, up till now, concentrated on this integration from the Workflow Management System's point of view, because a company's workflows describe the way the organisation works and must therefore be the heart of any companywide Information System.

eLearning is traditionally something that is purchased by organisations, both because few companies have the educational background to explain all the steps of the learning process, and because this process is innately very difficult. In addition, since the development of learning units is also expensive, companies might well fear that the costs which arise when the solution we have described is created might not justify the outcome.

We propose the following solution for these obstacles: The Workflow Management System is developed as an integral part of a company's Information System while the description, development, and presentation of learning units is outsourced as far as possible.

From a technical point of view, coupling an eLearning Environment to an existing Workflow Management System is the simplest way to implement such a solution. Learning material provided via the internet allows "instant updating, storage/retrieval, distribution, and sharing of instruction or information" (Rosenberg, 2001). This distributed delivery also means that we need not re- 
strict teaching materials and instruction to single activities, but can place them into a more general context.

In the previous section, our solution had been that a user who has to perform a certain activity for the first time must learn the learning unit $L U$ associated with this activity, as well as all other associated learning units required to understand $L U$ and which, in accordance with the learner tracking component, have not yet been learned, before s/he could conduct the task itself. By expanding the learning materials associated with the Workflow Management System to more general learning material available over the Internet, we can now take a further step: Whenever an employee has to work in a field in which s/he has no experience or background, the learning of the necessary material is added to her/his worklist, enabling the employee to undertake this work.

\section{SCENARIO-BASED DEVELOPMENT}

In our cooperation with one of the largest insurance companies in Germany, we are considering scenarios for the introduction of eLearning. In addition to the typical scenarios which arise in normal, every-day vocational education, we are also interested in demands for learning which result from specific risks or crisis situations. We are therefore considering not only the standard training programs developed by the company's Human Resource Management, but also the results of prior risk management analysis. The following example demonstrates this approach:

A typical insurance company has only a limited number of executive officers trained to handle damage and loss events, such as the death of a person as a result of an accident or murder. If a large number of people should suddenly die in a plane or train crash, or as a result of a terrorist attack (for example in situations such as those of September 11th 2001), there is a need to immediately increase the number of employees able to respond to this problem. This suggests a need for learning on demand which has to be satisfied very quickly. With conventional teaching methods such as seminars, this cannot be handled because of the large number of people who must be trained and for whom seminars (including traveling and hotels) must be organised. eLearning is the only really effective solution to this problem, enabling a company to provide the necessary training to an unlimited number of people at very short notice.

Impressive as this solution is, however, our potential approach goes even further: the Workflow Management System could recognise on its own that the amount of (special) insurance cases cannot be handled by the existing number of specialists and is able to identify the existing demand without external assistance. Using the information stored in the Learner Tracking System, the Learning System is able to identify those employees who have the lowest training demand to take over the required job, so that they can be selected rapidly for 
the specialist training required to undertake the necessary work. Furthermore, the system immediately associates the appropriate electronic learning unit to the respective employee's worklist.

Using the results of a former risk management analysis, many further application scenarios can be identified very easily. Workflow integrated eLearning is one way to be prepared for risks to come.

This solution is currently only a theoretical joining of eLearning and Workflow Management. But it is clear that the work we propose with Debeka could also apply to any well-structured organisation such as an airline, an electricity provider, or a hospital, where tasks are delineated and well understood.

\section{CONCLUSION}

This paper has provided an introduction to the concepts of eLearning environments and Workflow Management Systems, as a prelude to a proposal to integrate learning into employees' daily routines by adding the necessary teaching material to employees' worklists within their Workflow Management System. We believe that in the field of vocational education and training, existing solutions do not provide for situations such as the need to carry out tasks for which employees are not previously trained. This is something which can easily occur when, for example, a skilled employee is taken ill or otherwise is unexpectedly absent, or when there is a need to liaise with other companies for example when organisations are linked through integrated supply chain management systems or other eCommerce-based business activities.

The increasing trend to integrated supply chains, with their consequent need for multi-organisational linkages and exchange of information and knowledge, provides a further rich field for the Internet-distributed, Workflow Managementbased eLearning approach we have suggested in this paper.

We are currently working with one of the largest German insurance companies which is taking its first steps into an eCommerce environment. We will be testing our Internet-based, Workflow Management eLearning solution in this company over the next 18 months. Beside considering traditional situations for learning (and therefore for eLearning), we also focus on special situations in which risks are identified forcing companies to extend their existing workflows by learning units.

\section{REFERENCES}

(June 1996). Terminology \& Glossary. Workflow Management Coalition, http://www.wfmc.org/, issue 2.0 edition.

Beckman, T. J. (1999). The current state of knowledge management. In Liebowitz, J., editor, Knowledge Management Handbook. CRC Press, Boca Raton.

Block, H. and Dobell, D. (1999). The e-Bang Theory - Illuminismo Volume 2. Banc of America Securitas, Montgomery Division, educational industrie overview - equity research edition. 
Bodendorf, F. and Hofmann, J., editors (1993). Computer in der betrieblichen Weiterbildung. Oldenbourg Verlag, München.

Borghoff, U. M. and Pareschi, R., editors (1998). Information Technology for Knowledge Management. Springer, Berlin.

Dijkstra, S., Jonassen, D., and Sembill, D. (2001). The use of multimedia in education and training. In Dijkstra, S., Jonassen, D., and Sembill, D., editors, Multimedia Learning: Results and Perspectives. Peter Lang, Frankfurt.

Harhoff, D., Küpper, C., and Markart, V. (2001). e-learning in der weiterbildung - ein benchmarking deutscher unternehmen. Technical report, Institut fü Innovationsforschung und Technologiemanagement.

Kollinger, P., editor (2001). E-Learning: Eine Marktanalyse für Deutschland. Symposion Publishing, Düsseldorf.

Koulopulos, T. M. and Frappaolo, C. (1995). Electronic Document Management Systems - A Portable Consulting. McGraw-Hill, New York.

Rosenberg, M. J. (2001). E-Learning - Strategies for Delivering Knowledge in the Digital Age. McGraw-Hill, New York.

Sanchez, R. and Heene, A. (1997a). A competence perspective on strategic learning and knowledge management. In Sanchez, R. and Heene, A., editors, Strategic Learning and Knowledge Management. John Wiley \& Sons, Chichester.

Sanchez, R. and Heene, A. (1997b). Strategic Learning and Knowledge Management. John Wiley \& Sons, Chichester.

Sander, J. (1999). Mediengestütztes Bildungsmanagement. Gabler, Wiesbaden.

Subrahmanian, V. S. (1998). Principles of Multimedia Database Systems. Morgan Kaufmann Publishers, San Francisco.

Turban, E. (1992). Expert Systems and Applied Atrificial Intelligence. Macmillan.

Wiig, K. (1997). Knowledge management: Where did it come from and where will it go? Expert Systems with Applications, 4. 